\title{
THE DEVELOPMENT OF CONSTRUCTION INTERFACE INFORMATION MANAGEMENT SYSTEM
}

\author{
Fu-Cih Siao* and Yu-Cheng Lin \\ Department of Civil Engineering, National Taipei University of Technology, Taipei, Taiwan \\ *Corresponding author (s1340333@ntut.org.tw)
}

\begin{abstract}
Interface management plays an important role in construction management due to construction projects tend to be complex. A lot of organizations are joined and implement their own responsible activities. Furthermore, interfacerelated information is usually distributed in individual participants and not shared with others, and the information about interface problems that occur is also recorded in the large meeting minutes, causing the management of interfaces is more difficult for managers in this situation. This study presents a Construction Interface Matrix (CIM) approach to represent the interface issue-related information for project participants. This approach enables project participants and managers to directly acquire available information for managing interfaces efficiently without other data supporting. Overall, through utilizing the CIM approach, users can directly and efficiently acquire information related to the interface relationships among participants and interface conditions throughout a project. This study develops a Construction Interface Information Management (CIIM) system by integrating the proposed CIM approach and web technology for the construction phase of construction project. The test of the CIIM system is then conducted to illustrate how to support interface management during the construction project. Finally, based on the system test, results indicate the CIIM system can improve the interface management for project participants manage interfaces in the construction phase.
\end{abstract}

Keywords: Interface Management, Construction Management, Web Application, Management Information System.

\section{INTRODUCTION}

There are amounts of project participants are joined to a construction project which is always divided into subactivities, causing interfaces. Furthermore, these interface events may impact the project negatively regarding to schedule, cost, and quality [1], thus effectively managing and tracking interfaces of the construction is necessary. Currently, Interface Management (IM) has been attended by academic and practice and several approaches have been proposed to assist IM, such as Chua and Godinot (2006) proposed WBS matrix [2] and Chen et al. (2008) use Cause and Effect diagram to explore interface factors [1]. In practice, holding the collaboration meeting is a good approach for dealing with the interface issue that occur, but no preliminary discussion is made for the problem before the meeting, causing the low performance of the meeting progressing. And, the results of the interface problem solving are usually recorded in the meeting minutes. But, it is difficult that managers manage and track interface problems due to large amounts of records are increased and more interface results are stored in one meeting minutes. Also, although interface information sharing can decrease interface problems of the construction [3], information is usually not shared with other participants. Therefore, in order to address problems above, this study proposes the Construction Interface Matrix (CIM) approach to support construction IM, and this study also combines the CIM approach with the web technology to develop Construction Interface Information Management (CIIM) System that provides the dynamic interface information presentation for participants, enhancing the effectiveness of managing and sharing interfaces. Moreover, the primary objectives are as follows: (1) sharing interface information for project participants effectively, and (2) managing and tracking effectively interface issues of a project for users utilizing the CIM approach. 


\section{LITERATURE REVIEW}

IM is to make the communication and control for the interface issues by the systematic procedure [4], and the main works are that identifying which interfaces existed among systems or units and managing interface problems. If the management of interface issues is not well, they may become more complex. In order to achieve successful IM, the various types of interfaces should be identified along with how they may affect a project [5]. In the literature, some interface types had been identified, including product and project interfaces [6], time, technical, geographic, and social interfaces [4], static and dynamic interfaces [7], personal, organizational, and system interfaces [8]. However, project participants usually tend to their viewpoint, causing the construction information is not shared such as changes and interfaces information, thus increasing the chance of arising problems for successors. Hence, increasing interactions among participants should have benefits for the construction phase. And, the CIIM system focuses on the solution of communication among participants and provides a simple platform to manage interfaces effectively and efficiently throughout a project.

Based on the literatures and interview with experts, the procedure of IM is proposed to support IM (see Table 1).

\section{METHODOLOGY}

\subsection{PARTICIPANTS-BASED INTERFACE MATRIX CONCEPT}

Although the interface matrix approach is not a new method for IM, the CIM approach is novel concept to assist construction IM. The CIM approach can present the interface relationships among project participants in interface issues and provide the information about the status of issues. The CIM approach is formed by crossing vertical factors for the participant and event with a horizontal factor for the participant. The cells of the matrix can be marked to determine the work range for project participants and to record information about interface issues. The CIM approach provides interface information presentation service by using a simple form to enable project managers and participants to simply and effectively handle the condition of interface problems that occur. The advantages of CIM approach in construction IM are as follows: (1) project participants and managers can efficiently know the status of interface issues that occur, and which participants are joined in each interface event, (2) project participants and managers can acquire the interface status information without other data supporting, and (3) the CIM approach is to summarize the interface events content, further presenting the interface relationships and abstracts among participants clearly regarding to each interface event. Figure 1 shows the conceptual application in IM by the use of CIM approach. Additionally, there are two sheets are applied to assist IM works. First, in order to support the connections between works, the notice sheet has been applied in this study. Each sheet records the preceding activity's scope, duration, and interface issues. The predecessor has to send the successor this sheet before the activity finished, so the successor can know the condition of the predecessor's work and propose an interface problem he found and request a response from

Table 1. The description of construction interface management procedure.

\begin{tabular}{|l|l|}
\hline \multicolumn{1}{|c|}{ Phase } & \multicolumn{1}{c|}{ Description } \\
\hline Interface Collection & The interface proposer collects all problem-based documents/data to illustrate the problem. \\
\hline $\begin{array}{l}\text { Interface } \\
\text { Identification }\end{array}$ & $\begin{array}{l}\text { The interface proposer must identify the related participants, the position of the problem, and the } \\
\text { possible impact on this project. Then, he must propose the interface issue sheet in the system. }\end{array}$ \\
\hline $\begin{array}{l}\text { Interface } \\
\text { Submission }\end{array}$ & $\begin{array}{l}\text { After the manager acquires this issue sheet, he can know the detailed information related to the } \\
\text { problem and check related-participants' works from the event-based matrix. Then, the manager } \\
\text { can submit this issue to open the communication environment. }\end{array}$ \\
\hline $\begin{array}{l}\text { Interface } \\
\text { Communication }\end{array}$ & $\begin{array}{l}\text { An online communication environment is opened to generate solutions via discussion among } \\
\text { interface-related participants. }\end{array}$ \\
\hline $\begin{array}{l}\text { Interface } \\
\text { implementation }\end{array}$ & $\begin{array}{l}\text { After implementing problem-solutions, the manager can efficiently manage and track the status of } \\
\text { all interface issues using the CIM approach. }\end{array}$ \\
\hline Interface Close & $\begin{array}{l}\text { When this problem has been solved and does not need to be reconfirmed by identified managers, } \\
\text { the efforts of implementing problem-solutions and resolution date must be updated in the system. }\end{array}$ \\
\hline
\end{tabular}




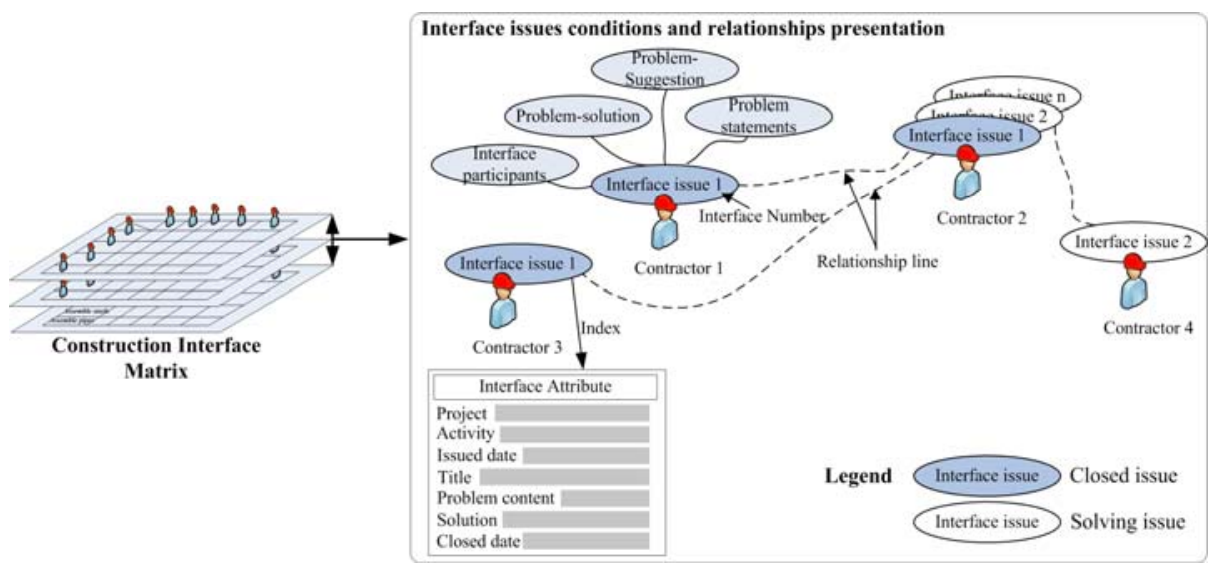

Fig. 1 The CIM application in construction interface management.

the predecessor. And second, each interface problem is proposed by using the interface issue sheet. In the interface issue sheet, descriptions of work scope, the interface problem, the interface response, and the problem-solution are included. When managers have identified interface problems solved, efforts of the solution implementation and the resolution date have to be recorded in the interface issue sheet. By utilizing the notice sheet and interface issue sheet, interfaces will be clearer during the construction phase of a project. Also, the CIIM system is designed to access the related information from the interface issue sheet to form the matrixes, enabling managers and participants can handle interfaces during the construction.

\subsection{PARTICIPANTS-BASED INTERFACE MATRIX} FRAMEWORK

The proposed CIM is multilevel and includes a construction events matrix, an interface presentation matrix, and an interface status matrix. First, the construction events matrix displays assignments for each participant by input marks in related cells. Second, the information of all interface issues is recorded in the interface presentation matrix. This matrix present the all interface issues and interface relationships among project participants, and recorded information includes interface name (as same as interface subject) and response times. The interface presentation matrix just provides all interface issues, if the large amounts of issues occurred, users will have difficulty to know how many problems exited among project participants, and users also do not know the condition of dealing with issues in only interface presentation matrix.
Therefore, such situation also is considered during the CIM development. The status of interfaces among project participants is presented in the interface status matrix. In this matrix, the recorded information includes the number of interface issues and the number of closed interface issues, and such information will be distributed in related cells of the matrix to indicate the status of dealing with issues for each participant. Utilizing three matrixes, project managers and participants can effectively acquire the information about assignments and interface issues.

\section{SYSTEM IMPLEMENTATION}

The CIIM system is designed and developed based on the MI matrix approach. The CIIM system is applied on Microsoft Windows XP with Internet Information Services (IIS), such a system environment as a web server. The CIIM system is built by ASP.NET. ASP.NET provides an approach to create dynamic web application and it can be used to design and develop the friendly-user interface of the CIIM system. There are three distinct layers in the CIIM system, as follows: the presentation layer, the business layer, and the data access layer. Each layer has its own works to support the system. First, the presentation layer defines the level of browsing information with administrators and normal users. Users can obtain and propose any interface information via a browser such as Internet Explore (IE) to connect in this system. Administrators not only can obtain requirements from this system but can also control and manage these interface data via the browser. Moreover, the proposed CIM approach can also be applied by administrators and normal 
users. The business layer consists of several application functions to support the system working. These applications include indexing, interface matrixes, interface sharing, and communication functions. Finally, the data access layer provide a stored function for interface data within Microsoft Access Server 2003 database, and administrators must backup those data to avoid losing and missing any interface information related to construction (see Fig. 2). Also, the CIIM system provides five services for IM, including the interface events matrix, the interface presentation matrix, the interface status matrix, online communication, and the interface sharing.

Through interview with three experts, this study summarizes different opinions to plan modules of the CIIM system. These modules are as follows:

\section{Interface matrix module:}

This module provides the interface matrix presentation service based on the CIM. Via this module, the system will automatically collect information to create three types of interface matrixes for users manage and track interfaces.

\section{Interface searching module:}

This module provides a convenient tool for users acquire any interface information they want. Construction Company has large database about interfaces so this system can help users obtain interface information efficiently through data searching functions.

\section{Online communication module:}

This module which likes Forum provides a channel to let users of the construction exchange opinions immediately regarding to the selected interface issue.

\section{Interface issue submission module:}

This module provides a function for users propose interface issues. When users find the problem, they can use this module to make an interface issue sheet, and then starting the IM procedure.

\section{Interface information sharing module:}

This module is developed based on the notice sheet. Utilizing this module, the successor can acquire the information about the construction condition of the predecessor, improving the interaction among participants and interface information sharing.

\section{SYSTEM TEST AND EVALUATION}

In order to evaluate the effectiveness of the CIIM system, the CIIM system is tested with the new building project. In the decoration engineering of this project, the mechanical and electrical pumping (MEP) activities must be finished before the lightweight metal beams of the roof activity starts, but the MEP works delayed while the succeeding activity still started based the construction schedule and had finished, thus causing the interface problem which some parts of the completed structure can be destroyed and the extra-cost is added for the predecessor. In this study, the CIIM system is used to improve the IM for this interface issue (see Fig. 3). First, before the lightweight metal beams of the roof activity starts, the responsible participants can propose the interface issue in the CIIM system, called no notice sheet, if they acquire no notice sheet. Through this issue sheet submission, the related participants must make the responses to this issue, and the successor can request a determination from the manager such as whether the succeeding works start on schedule. Furthermore, when the problem is proposed, the related matrixes are generated automatically in the system. Participants and managers can get the information of the status of this issue during the interface implementation.

In order to identify the effectiveness of the system, this study introduces the process of the CIIM system application in the test above to three experts, who two of them have special experience over 8 years and another one has 20-year experience. All of them approve the management and tracking of interface problems throughout a project are improved by the CIM approach, and they also consider the notice sheet is a good tool for the IM because the successor can know the condition of the predecessor's works, enabling the successor to respond early such as changing the work plan to address the latest situation of the construction. Consequently, test results indicate the CIIM system is an effective IM tool for the construction phase.

\section{CONCLUSION}

A construction project is always divided into large amounts of activities which will be done by joined participants, and interface information is usually distributed in each participants and recorded in the meeting minutes, causing it is hard to manage and track interfaces for managers. Hence, 
a novel CIM approach is proposed in this study, which includes an interface events matrix, an interface presentation matrix, and an interface status matrix. Moreover, CIM is integrated with web technology to develop the CIIM system, which provides the dynamic interface information presentation service. Besides the CIM, the notice sheet and interface issue sheet also are applied in this system for users share interface information and propose problems they found. Finally, the system test and interview have been done to evaluate the effectiveness of the system, and results indicate the CIIM system provides an effective IM tool for the construction phase.
The recommendations are found during the interview, they are as follows: (1) project managers should join IM team since the CIM requires them to assign and manage related assignments, (2) e-mail service is very important for IM to notice all responsible participants to respond the interfaces in the CIIM system so participants should check mails once time per day, (3) policy and strategy must be considered to encourage the use of the system because the effective use requires that changes be made to almost every aspect of a firm's business, and (4) the training and workshops for the CIIM system are necessary and useful for all users.

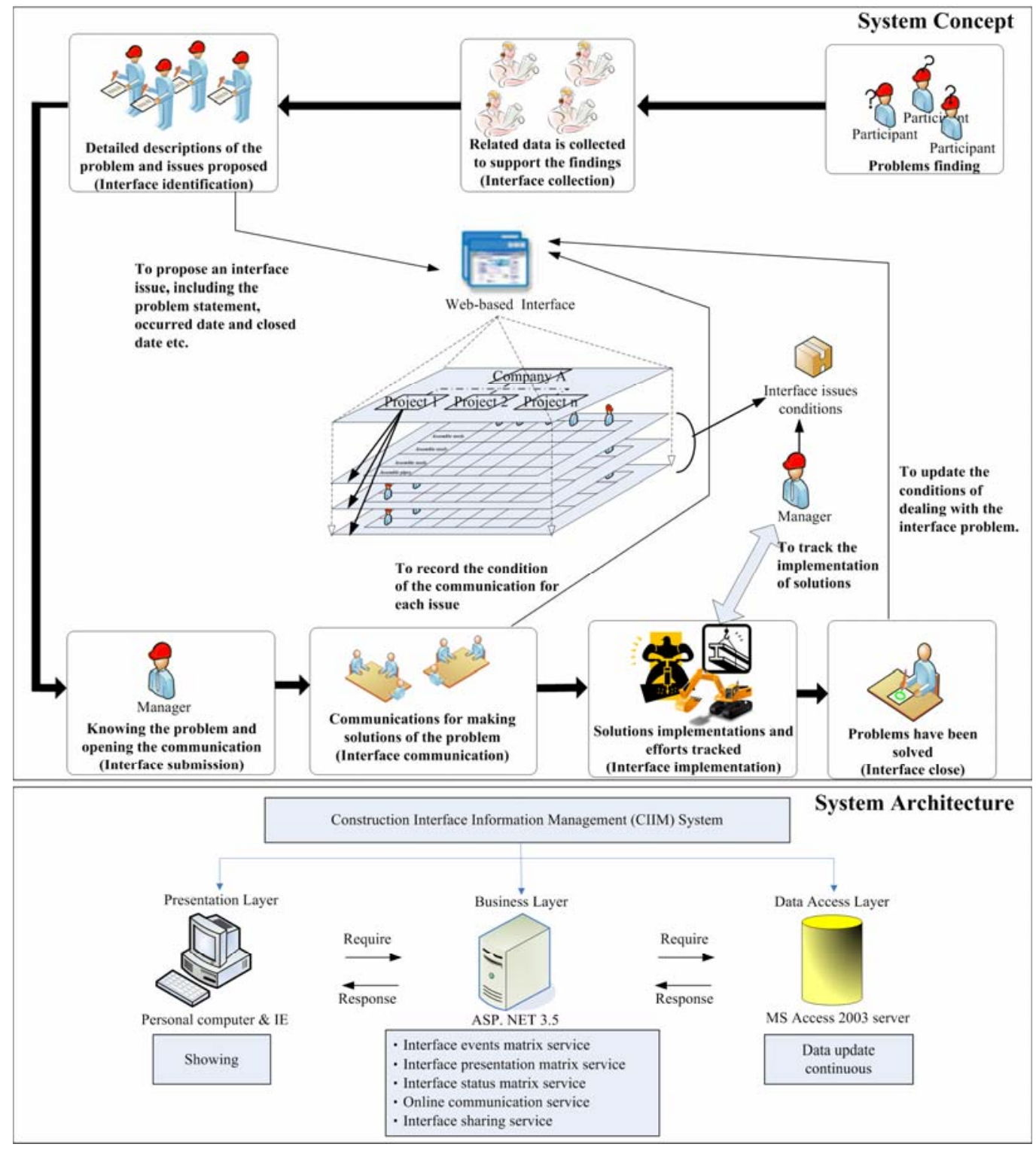

Fig. 2 The framework of the CIIM system. 


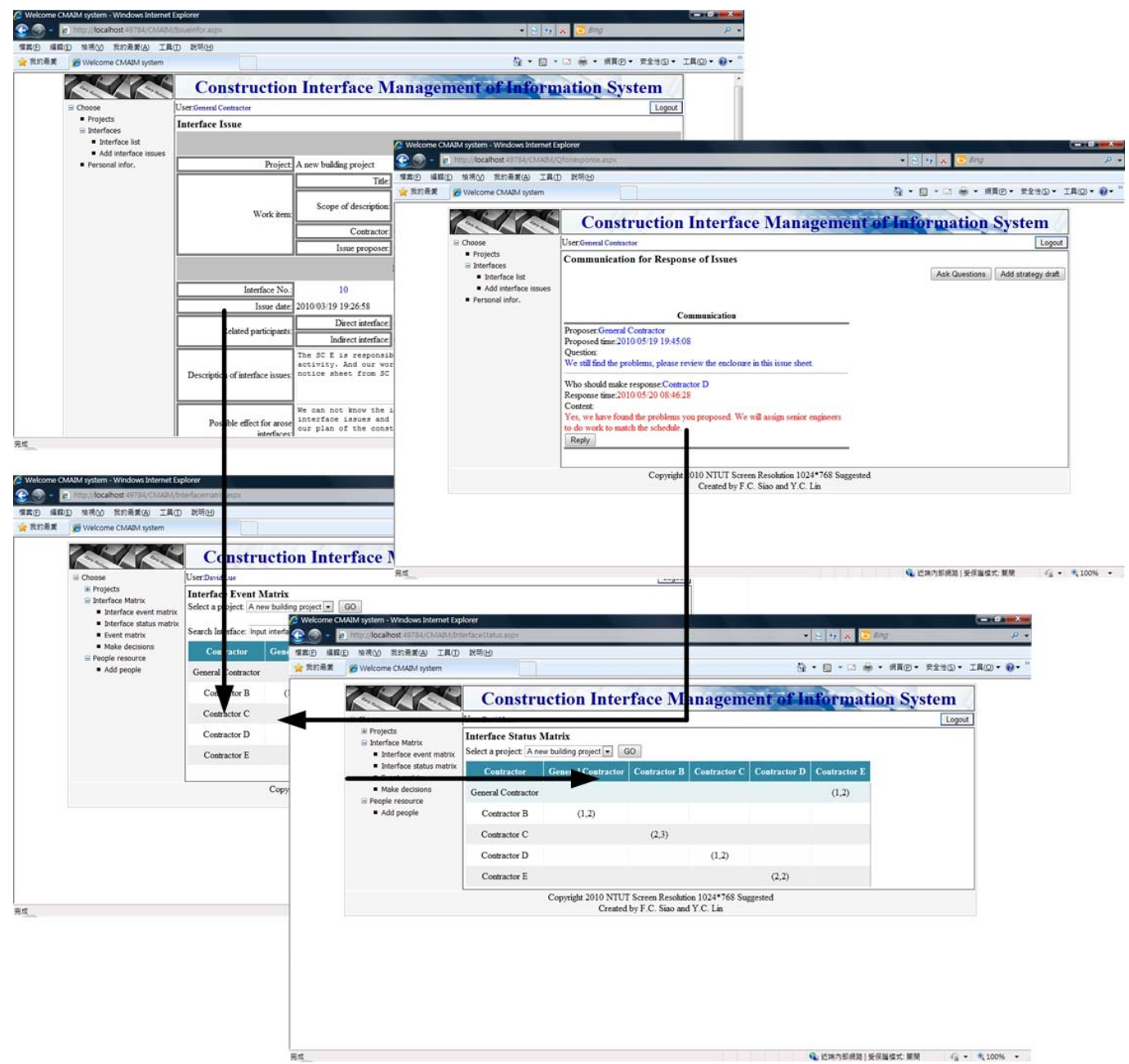

Fig. 3 The screen of the CIIM system

\section{REFERENCES}

[1] Chen, Q., Reichard, G. and Beliveau, Y., Multiperspective approach to exploring comprehensive cause factors for interface issues, Journal of Construction Engineering and Management, 134(6), pp.432-441, 2008.

[2] Chua, D. K. H. and Godinot, M., "Use of a WBS matrix to improve interface management in projects," Journal of Construction Engineering and Management, 132(1), pp.6779, 2006.

[3] Lin, Y.C., "Developing Construction Network-Based Interface Management System,” 2009 Construction Research Congress, ASCE, pp.477-486, 2009.

[4] Healy, P., Project management: Getting the job done on time and in budget. Butterworth-Heinemann, Newton, Mass, 1997.
[5] Pavitt, T. C. and Gibb, A. G. F., "Interface management within construction: in particular, building façade,” Journal of Construction Engineering and Management, 129(1), pp.8-15, 2003.

[6] Archibald, R. D., Managing high-technology programs and projects. Wiley, New York, 2003.

[7] Morris, P. W. G., "Managing project interfaces—Key points for project success.” Chapter in Project management handbook, by D. I. Cleland and W. R. King (editors), Van Nostrand Reinhold, New York, 1983.

[8] Stuckenbruck, L. C., "Integration: The essential function of project management.” Chapter in Project Management Handbook, by D. I. Cleland and W. R. King, Van Nostrand Reinhold, New York, 1993, pp. 37-58. 